\title{
LOS BENEFICIOS DE ESPAÑA DURANTE LA GRAN GUERRA. \\ UNA APROXIMACION A LA BALANZA \\ DE PAGOS ESPAÑOLA, 1914-1920*
}

CARLES SUDRIA

Universidad de Barcelona

\begin{abstract}
En modesto homenaje al profesor Joan Sardà, economista ejemplar.
\end{abstract}

\section{Introducción}

Hace más de cuarenta años, en 1948, en su obra pionera sobre la política monetaria y las fluctuaciones de la economía española en el siglo xIx, el profesor Joan Sardà escribía: «... el conflicto europeo [de 1914-1918] tuvo repercusiones económicas muy favorables para España. En pocos años permite pagar casi del todo la deuda exterior en capitales. Se nacionaliza la Deuda exterior y se recupera por los españoles la gran mayoría de las inversiones tenidas por extranjeros en España [...]. A base de este aumento extraordinario de riqueza ganado durante la guerra europea, continuó fun. cionando la economía española en los años siguientes»'. Estas frases formaban parte del capítulo que dentro de aquel libro el profesor Sardà dedicaba al estudio de la balanza de pagos española. Pese a quedar fuera del ámbito temporal de su estudio, se avanzaba alli una cifra tentativa de los beneficios que la economía española, en su conjunto, pudo obtener durante el conflicto bélico.

Desde aquella fecha ya tan lejana, los estudios referidos a la evolución de la economía española durante la Primera Guerra Mundial han sido muy numerosos y, en algunos casos, exhaustivos y de gran calidad ${ }^{2}$. Sorprendente-

" Distintas versiones de este trabajo han sido presentadas al III Seminario de His. toria Económica Cuantitativa (Alcalá de Henares, diciembre de 1988) y al Seminario del Departamento de Historia Económica de la Universidad de Barcelona. He recibido críticas y sugerencias del máximo interés de muchos compañeros. No pudiendo citarlos a todos, quiero expresar mi especial agradecimiento a Albert Carreras, Francisco Alcalá, David Reher, Blanca Sánchez Alonso, Leandro Prados, Pablo Martín Aceña, César Yánez y Antonio Tena. Mención muy destacada debo hacer de Francisco Comín, crítico inte. ligente y acerado de este trabajo en el primero de los seminarios citados.

Sardà (1987), p. 240.

2 El más importante y caracterizado de estos estudios es el de Roldán y García Del- 
mente, sin embargo, el tema de las cuentas exteriores de España no ha vuelto a ser tratado en profundidad. En todos y cada uno de los trabajos citados se confiere al sector exterior un papel decisivo en la evolución de la economía española en aquellos años, pero en ninguno de ellos se ha intentado la reconstrucción de las magnitudes básicas de nuestra balanza exterior. La mejor de las aportaciones realizadas al tema por los contemporáneos, la de Arthur N. Young (1920), citada por Sardà, no ha vuelto a ser utilizada.

El objeto de estas líneas es, justamente, el de presentar una aproximación a la balanza de pagos espanola en los años que van de 1914 a 1920, con la esperanza de que ello pueda dar lugar a una nueva reflexión sobre los efectos que tuvo sobre la economía española el estallido y desarrollo de la Primera Guerra Mundial.

La adopción de ese lapso temporal se debe a que las alteraciones producidas directamente por la guerra en las cuentas exteriores de España se prolongaron hasta 1920. A partir de 1921 podemos considerar que se vuelve a la normalidad, aunque en algunos aspectos la estructura de ingresos $y$ pagos sea diferente a la de los años anteriores al conflicto.

Un primer apartado va a dedicarse al estudio de la balanza comercial, para pasar después a la balanza de servicios y transferencias. En las últimas secciones se tratará del uso dado a los excedentes obtenidos y de las consecuencias que pudo tener sobre la economía interna el saldo positivo de las balanzas exteriores.

\section{La balanza comercial}

El principal escollo con el que ha topado el estudio del sector exterior español durante la Gran Guerra ha sido, naturalmente, el problema de las valoraciones. Como es bien sabido, a las cantidades de cada producto importadas y exportadas, se les otorgaba en las estadísticas oficiales un valor que, de hecho, no correspondía al precio real del producto. Por si ello fuera poco, entre 1913 y 1920 , en unos años de enormes alzas de precios, las valoraciones aplicadas se mantuvieron constantes. Las cifras oficiales de importación y exportación de este período carecen por ello de toda significación que no sea la de reflejar la evolución "cuántica» - a precios constantes- de las magnitudes citadas, y aún ello imperfectamente.

Para paliar este problema existen dos caminos distintos, ambos extrema-

gado (en colaboración con Juan Muñoz) (1973). José Luis García Delgado ha publicado posteriormente varios trabajos sobre el mismo período, García Delgado (1981, 1983 y 1984). Otros trabajos igualmente importantes que se refieren al período aquí estudiado son los de Fontana y Nadal (1980) y Maluquer de Motes (1987). 
damente inseguros y fatigosos. El primero consiste en valorar de nuevo un conjunto suficientemente significativo de productos y estimar, mediante la muestra obtenida, el valor real de las importaciones y exportaciones totales. Las dificultades para hallar series de precios nacionales o extranjeras para un número amplio de productos y la multiplicidad de bienes que se incluían en muchas partidas arancelarias, hacen que esta via, además de laboriosa, obligue a aceptar aproximaciones que se basan en muestras que sólo abarcan un porcentaje muy reducido del total.

El otro camino disponible para superar la insuficiencia de nuestras estadísticas de comercio exterior consiste en recurrir a las estadísticas de aquellos países que eran nuestros principales clientes y abastecedores. Este procedimiento resulta inicialmente más simple, pero exige mantener una confianza absoluta en las estadísticas de esos países y, además, obliga a valorar global. mente los costes de transporte de los productos de un país a otro, ya que, naturalmente, esas estadísticas muestran el valor de las importaciones o de las exportaciones según los precios de los productos en los puntos de entrada o salida de cada país y no en los de llegada o salida de España. Como tendremos ocasión de comentar más adelante, el cálculo de estos costes de transporte resulta extremadamente arriesgado, especialmente en años tan agitados como los que aquí pretendemos estudiar.

Las estimaciones hasta hoy disponibles sobre el comercio exterior español durante la Primera Guerra Mundial se han realizado por el primero de los procedimientos indicados. La primera de ellas se debe al destacado economista Josep A. Vandellós y data de 1931; la segunda ha sido aportada recientemente por Antonio Tena ${ }^{3}$. Como se puede observar en el cuadro 1, los resultados obtenidos en ambos trabajos presentan algunas similitudes y también algunas discordancias. Estas son especialmente relevantes para los años 1915 y 1916 y resultan espectaculares para 1920. En el primer caso los saldos netos de uno y otro año tienden a compensarse, con lo que la valoración global del período resulta poco afectada. Para 1920, en cambio, la discrepancia resulta extremadamente grave y exige observarla con algún detenimiento.

La diferencia entre ambas valoraciones para 1920 reside, principalmente, en la mayor intensidad que Antonio Tena otorga a la recuperación de las importaciones. De aceptarse las cifras que propone, todo el superávit co-

'Vandellós (1931) y Tena (1985). El procedimiento seguido en ambos trabajos es distinto. Vandellós supone válida la valoración de 1913, y a partir de ese año efectúa una estimación de los precios de algunos productos de cada clase del arancel, a través de los cuales otorga un valor al conjunto de la clase y, finalmente, a la cotalidad de las importaciones $y$ exportaciones. Tena ha optado por un procedimiento más riguroso al escoger como base de estimación 13 mercancias de importación y 16 de exportación, homogéneas y con precios verificables, pero que - para el período que aquí tratamossólo cubren un porcentaje aproximado del 25.30 por 100 del total de importaciones, y del 35.40 por 100 de todas las exportaciones. 


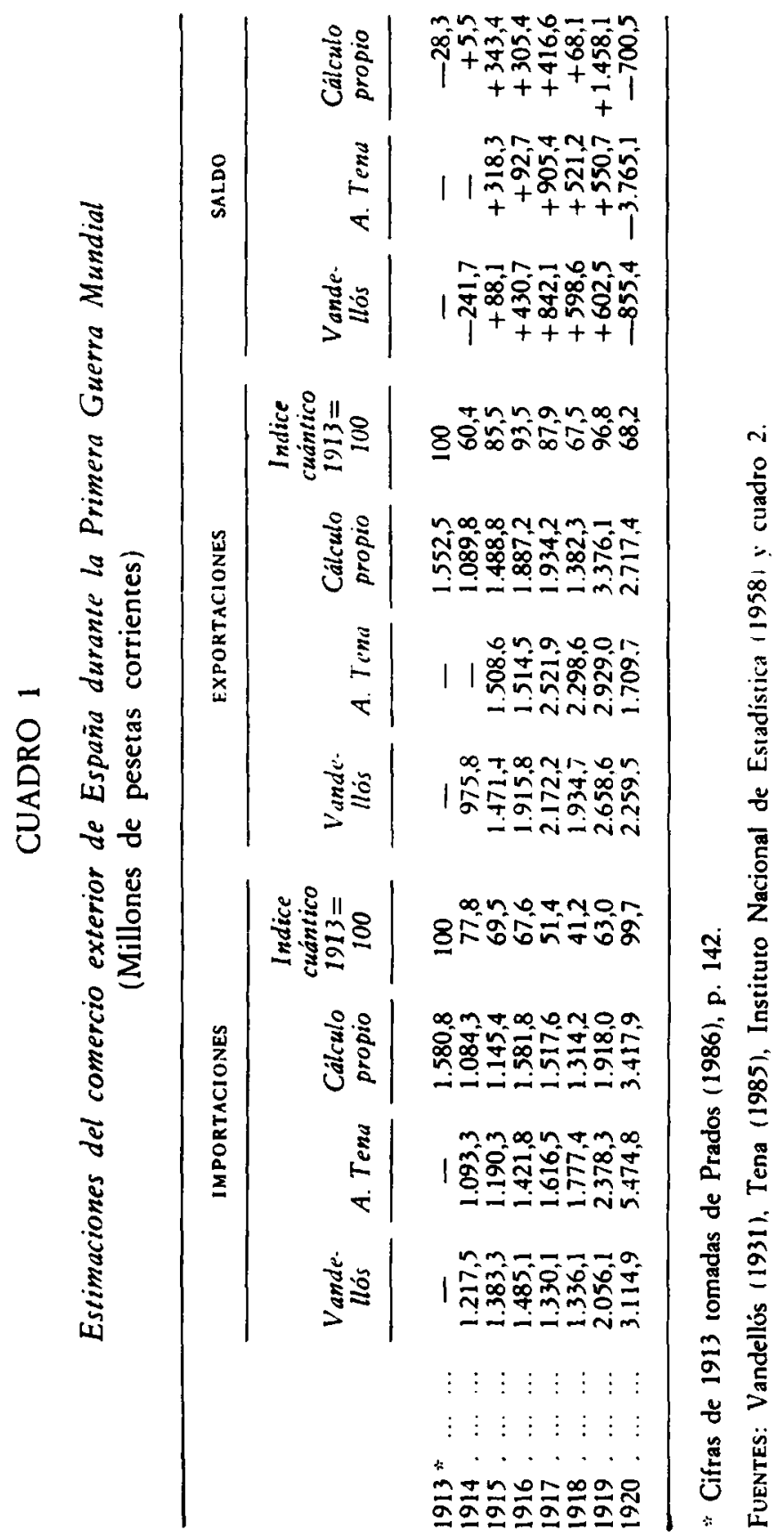


mercial obtenido entre 1915 y 1919 quedaría eliminado y convertido en un severo déficit al incluir 1920. Tales estimaciones resultan del todo inconsistentes con la evidencia que poseemos de un incremento notable de las reservas de oro del Banco de España. de la repatriación masiva de títulos españoles hasta entonces en manos extranjeras y del mantenimiento de fuertes saldos en moneda extranjera por residentes españoles. Si la balanza comercial hubiera resultado efectivamente deficitaria, habría que atribuir todo ese saldo financiero favorable (más de 4.000 millones de pesetas) a los ingresos obtenidos por servicios y transferencias, lo que resulta, como veremos, totalmente inverosímil ${ }^{4}$.

Con el fin de contrastar los resultados que estamos comentando, he procedido a realizar una nueva estimación del comercio exterior español por el segundo de los procedimientos antes indicados, esto es, recurriendo a las estadísticas de aquellos países con los que existía una más intensa relación comercial ${ }^{5}$. He utilizado los datos correspondientes a los cuatro principales socios comerciales de España en aquellos años: Francia, el Reino Unido, los Estados Unidos y Argentina. Durante el período 1914-1920, estos cuatro países aportaron de media el 60,4 por 100 de todas las importaciones españolas y recibieron el 69,7 por 100 de las exportaciones totales. Las cifras que muestran las columnas (a) del cuadro 2 provienen de las publicaciones oficiales de esos paises y han sido transformadas en pesetas corrientes aplicando el tipo de cambio medio de cada año.

Como se ha indicado más arriba, estas cifras corresponden al valor de los productos importados o exportados al llegar o antes de salir de cada país $y$, por lo tanto, es preciso deducir o añadir a ellos el coste del transporte para obtener los valores efectivos de las exportaciones (f.o.b.) e importaciones (c.i.f.) españolas.

El cálculo de estos costes de transporte resulta una tarea extremadamente compleja y siempre insatisfactoria. Una primera serie de dificultades deriva de la escasa información disponible, tanto en España como en el extranjero, y de las profundas divergencias que a menudo presentan las distintas fuentes. En el caso que nos ocupa he tenido que recurrir en algunas

- La causa del error debe residir en los precios en pesetas utilizados para el año 1920, en el que hubo violentas fluctuaciones en los cambios y en los precios internacionales. Una comparación con los precios interiores españoles para algunos productos podria ayudar a dilucidar la cuestión.

'Palafox (1980) utilizó este mismo procedimiento para estimar la evolución del comercio exterior español durante la primera mitad de los años 1930. Tena (1985) realiza un ejercicio similar al que aquí se propone, pero no llega a concluirlo. Entre los resultados parciales que ofrece y los obtenidos aquí se observan algunas diferencias relativamente pequeñas para las importaciones pero muy notables para las exportaciones. De concluirse la estimación en base a los cálculos primarios of recidos por Tena, el saldo en la mayoría de los años considerados sería negativo. 


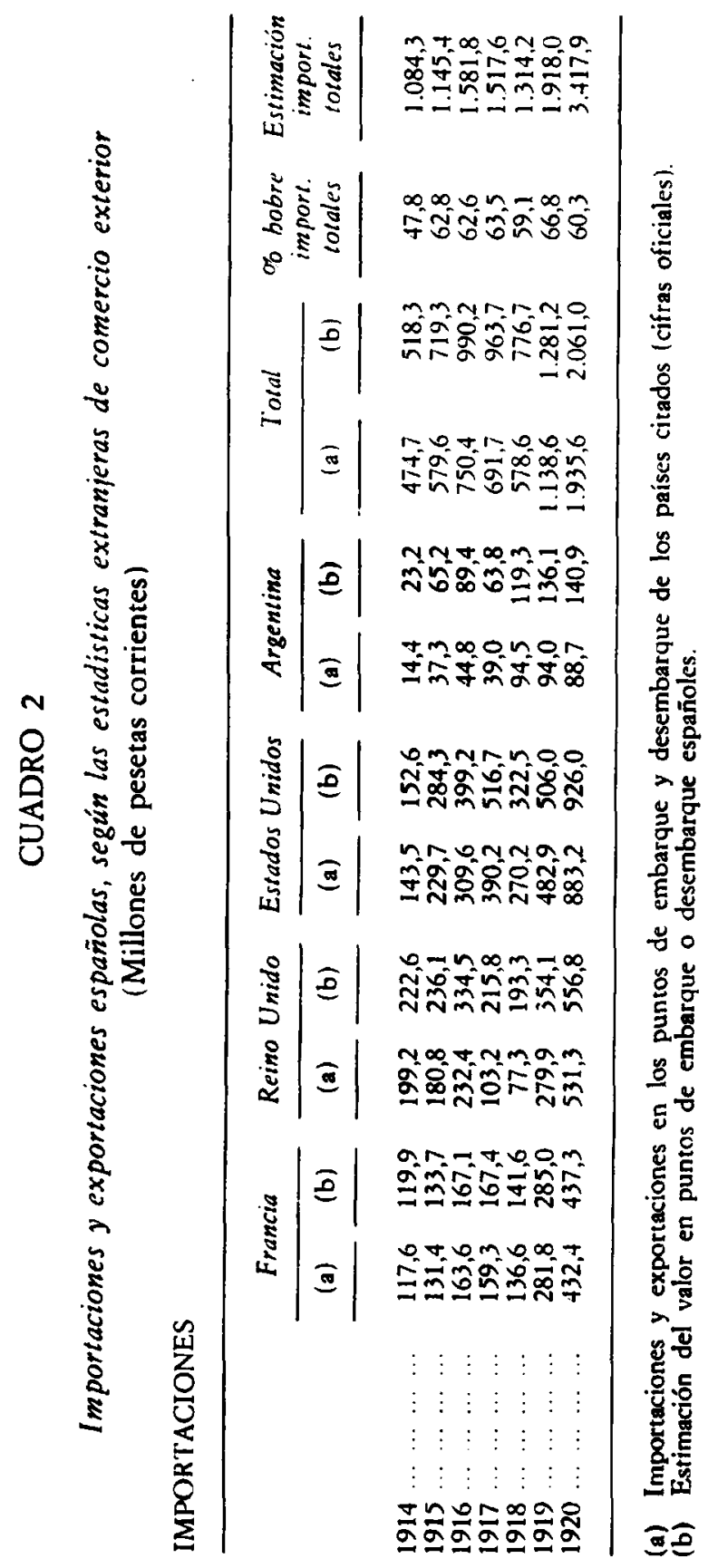




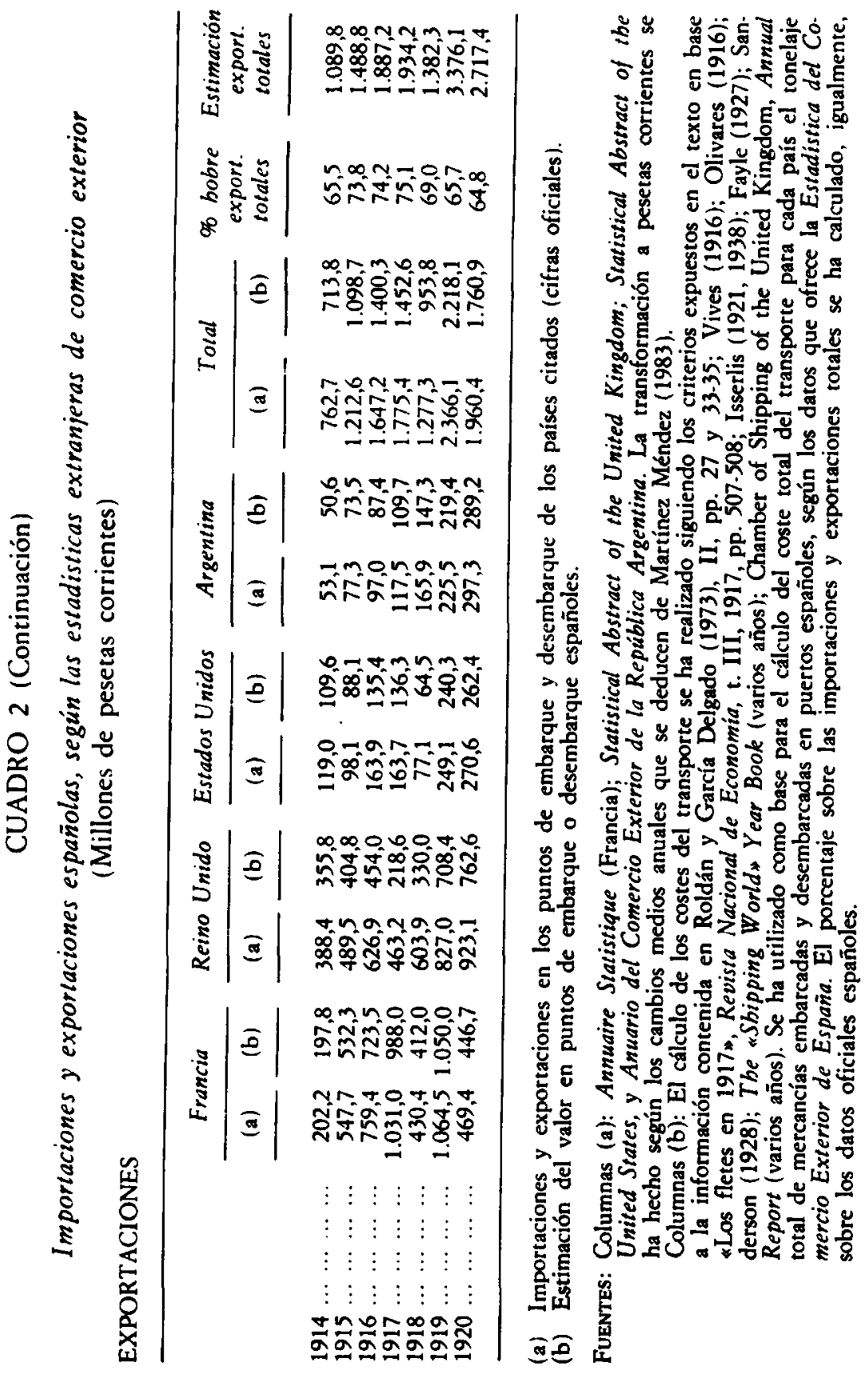


ocasiones a cifras correspondientes a puertos no españoles o de carácter general, especialmente para las líneas transoceánicas. El problema mayor, sin embargo, lo impone la extremada dispersión de los precios aplicables. Cada producto, según su volumen, peso, etc., tenía una tarifa propia, como la tenía, naturalmente, cada ruta establecida entre un puerto extranjero y otro español. Siendo imposible un estudio producto por producto y puerto por puerto, se ha adoptado para cada pais un coste de transporte medio por tonelada, otorgando un peso decisivo al producto que, en cada caso, mayor tonelaje aportaba al comercio bilateral (carbón y mineral de hierro, con el Reino Unido; cereales y algodón y piritas, con los Estados Unidos; etc...).

Es preciso señalar, además, que en estos años específicos el estallido y desarrollo de la guerra, las movilizaciones de bienes y de hombres y las medidas de intervención adoptadas por los beligerantes afectaron grandemente al comercio marítimo. Además de producirse una elevación enorme de los fletes, la dispersión arriba indicada se multiplicó hasta el infinito al ser distintas las tarifas según la nacionalidad, el barco, el carácter estratégico de la mercancía, la coyuntura bélica del momento, etc...

En definitiva, si las cifras de las columnas (a) del cuadro 2 merecen la confianza que se quiera otorgar a los servicios estadisticos franceses, británicos, norteamericano y argentinos, las que se reflejan en las columnas (b) resultan mucho más inseguras. Señalemos, para moderar la inquietud del lector, que estos posibles errores sólo afectarían a la diferencia incorporada respecto a las columnas (a) y que únicamente en el caso norteamericano los errores podrían alterar significativamente el resultado final.

El análisis de los resultados de esta nueva estimación y su contraste con los anteriormente expuestos permiten algunos comentarios. Empezando por las importaciones, nuestras cifras confirman que el efecto inmediato del conflicto fue un descenso sustancial de las compras al exterior, tanto en términos de cantidades (a precios constantes, índice cuántico, cuadro 1) como en el valor global. Una recuperación de los antiguos niveles se observa, en cuanto a los valores totales, en el año 1916, con una ligera tendencia a la baja hasta 1918. En 1919 se registra ya un incremento significativo, y en 1920 se produce una entrada masiva de productos extranjeros, que venían sin duda a cubrir una demanda remansada en los años anteriores. A destacar que, pese a esta recuperación, no se vuelven a alcanzar los niveles de importación anteriores a la guerra si eliminamos el efecto del alza de precios. Significativamente, España entraba en la década de 1920, más cerrada al exterior que antes de iniciarse el conflicto mundial.

La nueva serie de importaciones discrepa en diversos aspectos de las dos anteriores. Limitándonos únicamente a los movimientos interanuales, la nueva serie muestra una variabilidad mayor que las otras dos, aunque las diferencias 
realmente significativas sólo se producen para 1914 y 1915 , respecto a la serie de Vandellós, y para 1920 respecto a la de Tena. Según mis cifras, durante 1914 y 1915 las estimaciones de Tena estarían más ajustadas a la realidad, mientras que para 1920 serían las de Vandellós las más creíbles.

Volviendo al cuadro 2, resulta interesante comprobar cómo Estados Unidos asumió durante la guerra el papel de principal suministrador de España, sustituyendo a Alemania y, parcialmente, a Francia. Argentina también incrementó sustancialmente su participación en el mercado español, en especial en los últimos años del período. El caso británico destaca por las profundas variaciones que se observan, estrechamente vinculadas a las vicisitudes de la guerra naval.

Por lo que se refiere a las exportaciones, las cifras no dejan lugar a dudas sobre el hecho de que el factor decisivo de la expansión hay que encontrarlo en el espectacular incremento de la demanda francesa. Sólo en 1919 y 1920 se observan aumentos destacables del valor de las exportaciones a los otros tres países analizados.

La evolución anual de las exportaciones muestra que el salto realmente importante se produjo en 1916, y que el punto máximo se alcanzó en el 1919 Si eliminamos el efecto de los precios (índice cuántico, cuadro 1) el alza se convierte en una violenta fluctuación en la que jamás se alcanza el nivel de 1913. Hay que tener presente, sin embargo, que las exportaciones fueron en ese año anormalmente elevadas y que el índice medio de los años anteriores hay que situarlo en torno a 70. Atendiendo a ello, también en términos de precios constantes se habría producido un incremento importante de las exportaciones.

Comparando la nueva serie con las anteriores se observa que existen notables diferencias en la evolución anual. Destaca el mayor ímpetu exportador que registra la nueva serie para los años finales del período $y$, también, la distinta forma en que se refleja el paréntesis de 1918. En este sentido es necesario recordar que existen abundantes testimonios de la existencia de transacciones clandestinas, que si principalmente iban dirigidas a los países centroeuropeos, también afectaban a los que aquí sirven de referencia.

En definitiva, la expansión de las exportaciones está fuera de toda duda, como también lo está que fueron los años 1916 y 1917 y, sobre todo, 1919 y 1920 - una vez terminada la contienda- los más favorables.

Respecto a los productos que protagonizaron esta expansión extraordinaria mis indagaciones se han limitado al caso francés, el más significativo. El cuadro 3 muestra los principales renglones de la importación francesa de España en los años que estamos estudiando. Como era de esperar, destaca el papel asumido por los tejidos -especialmente los de lana- objeto de demanda masiva para usos militares. Ello no obstante, merece la pena llamar la atención 


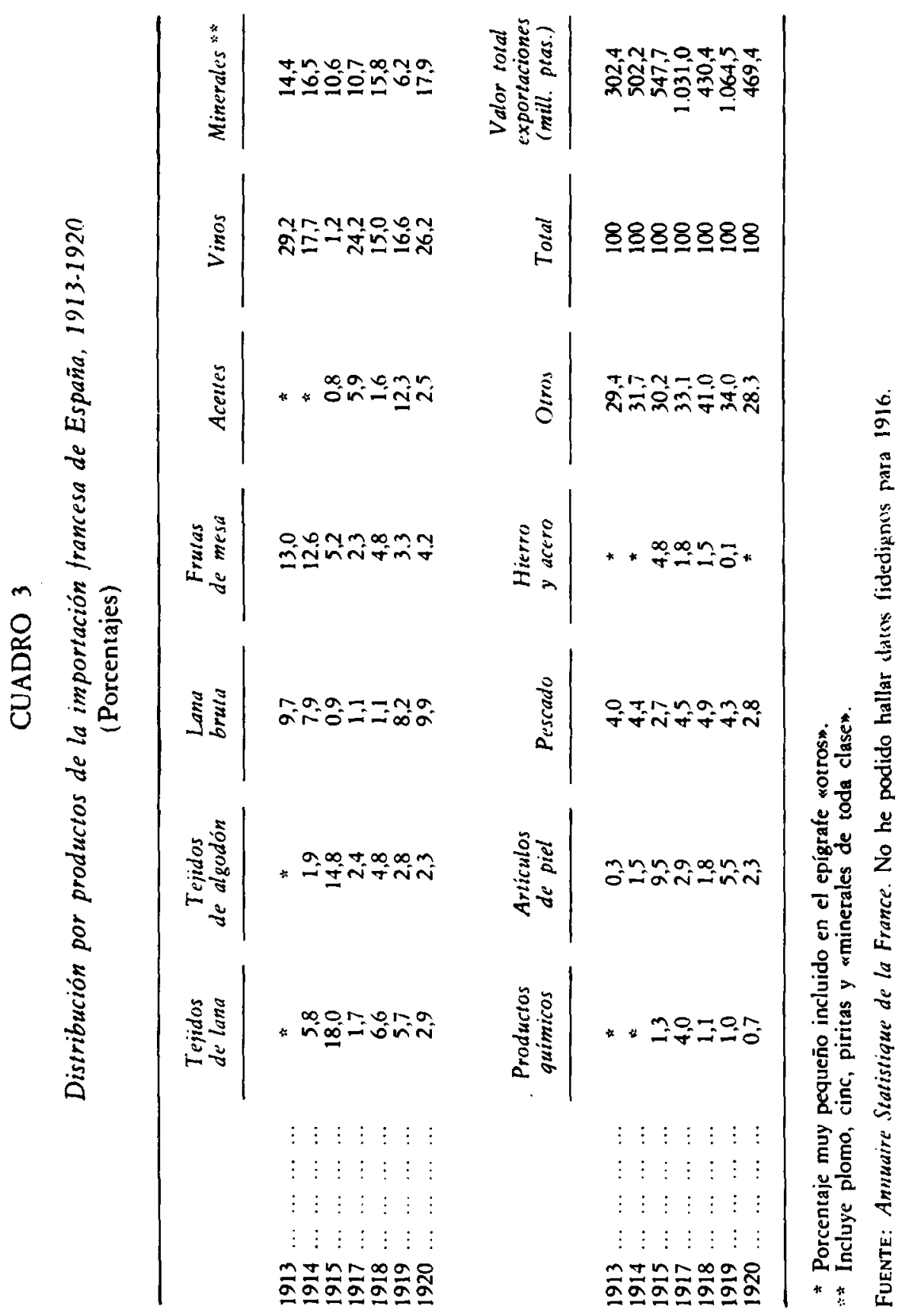


sobre el hecho de que las exportaciones tradicionales más importantes — vinos y minerales-, pese a perder peso relativo, mantuvieron una significativa participación, superior, en la mayoría de los años, a la de los propios tejidos. La fruta y la lana bruta p:irecen, por lo contrario, los productos más afectados por la dislocación del mercado francés. Cabe añadir, finalmente, que en determinados años adquirieron importancia puntual en las importaciones francesas de España el hierro y el acero, los productos químicos y los artículos de piel. En definitiva, la expansión exportadora vino protagonizada por algunos artículos que en circunstancias normales no salían de nuestras fronteras, y también por algunas de las exportaciones tradicionales.

Hechas estas referencias a importaciones y exportaciones, llega el momento de referirse a la evolución de la balanza comercial en su conjunto. Según la nueva serie que aquí presento, el superávit comercial del período 1914-1920 sería del orden de los 1.900 millones de pesetas. Es una cifra inferior a la propuesta por Young, pero superior a la ofrecida por Vandellós, que situaría el superávit de esos años en 1.460 millones $^{6}$.

Cualquiera que sea la estimación que se acepte, debe convenirse que se trata de una cantidad muy importante. Pensemos que el dinero legal en circulación en España en 1913 ascendía a 2.300 millones de pesetas y que - para poner otro término de comparación - la renta nacional española para ese mismo año era estimada por el propio Vandellós en 10.745 millones. Un superávit comercial de tal magnitud no se había dado, probablemente, en ningún otro periodo desde principios del siglo xix y había de tener notables consecuencias para la economía española?.

Las cifras agregadas en valor que estamos manejando no permiten establecer si el origen del superávit se debió a un incremento de las exportaciones netas reales o a una mejora de las relaciones reales de intercambio. En otras palabras, si el saldo positivo fue el resultado de un aumento del ahorro de los españoles o de una mejora de los precios relativos de nuestras exportaciones. Para hallar una respuesta correcta a esta cuestión sería necesario contar con precios de una muestra suficiente de productos importados y exportados. Una aproximación grosera y muy provisional puede alcanzarse comparando los índices de valor y los índices físicos de las exportaciones y las importaciones. Los resultados de esta operación (cuadro 4) permiten avanzar

- $\mathrm{Si}$ observamos sólo el período 1915-1919, para el que contamos con información homogénea, los saldos de todas las estimaciones disponibles son bastante próximos: Vandellós, 2.560 millones; Young, 3.000 millones; Tena, 2.390 millones; y la que
aquí se presenta, 2.590 millones.

; La estimación de la renta nacional en Vandellós (1977), p. 123. Sobre la evolución del comercio exterior y su relación con el desarrollo de la economía española antes y después de los años que aqui estudiamos, deben consultarse los trabajos de Prados (1982, 1984, 1986 y 1988) y Palafox (1986 y 1980). 


\section{CUADRO 4}

\section{Una aproximación a las relaciones reales de intercambio}

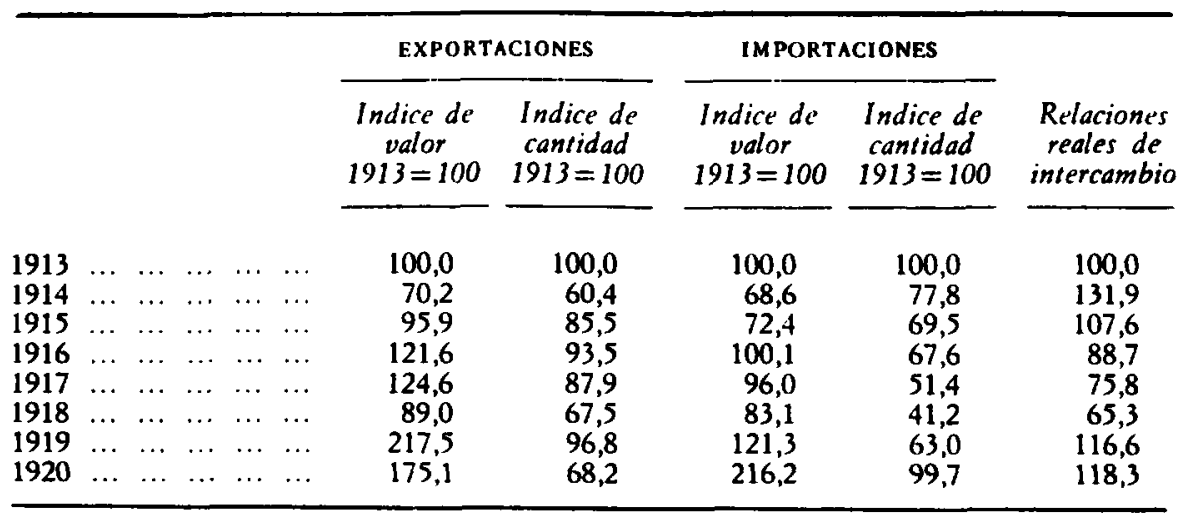

Fuente: Cuadro 1.

que muy probablemente los precios relativos de las exportaciones tendieron a empeorar, al menos entre 1916 y 1918. Una evaluación realizada por Tena (1989) por el mismo procedimiento pero sobre diferentes estimaciones de base, ofrece resultados todavía más negativos. Globalmente, en todo caso, no parece que quepa atribuir el superávit a una mejora de las relaciones reales de intercambio.

\section{La balanza de servicios}

El saldo positivo de la balanza comercial no fue la única fuente de ingresos exteriores extraordinarios que tuvo España en esta etapa. Los servicios y transferencias desempeñaron también un papel destacado. Veamos ahora cuál fue su importancia.

Para determinar los saldos de las cuentas de servicios y transferencias no contamos, desgraciadamente, con soporte estadístico directo. Sólo a través de referencias indirectas y cálculos aproximados podremos avanzar algunas conjeturas.

Por lo que se refiere a los servicios, las únicas partidas relevantes eran los fletes y los pagos y cobros del exterior por rentas de inversiones. Por razones obvias, el turismo no pudo ser en estos años un factor relevante de entrada de recursos. Empecemos por los fletes. 
La aportación del transporte marítimo a la balanza de pagos se corresponde con los ingresos obtenidos por las empresas navieras españolas en la navegación exterior. Habiendo estimado la balanza comercial en valores c.i.f. para las importaciones (flete incluido) y f.o.b. para las exportaciones ( $\sin$ flete), los ingresos obtenidos por empresas españolas tanto en el tranporte de productos españoles al extranjero como por el de productos extranjeros hacia España, han de considerarse como ingresos de la balanza de pagos española. Como es natural, también deben contabilizarse los ingresos por transportes efectuados por barcos españoles entre países extranjeros.

Como es bien sabido, el estallido de la guerra, en el verano de 1914, alteró completamente el panorama del transporte marítimo internacional. El interés de los contendientes en evitar la arribada de suministros al enemigo y la propia dinámica bélica convirtieron el transporte comercial en una arriesgada aventura. Una parte de la flota mercante mundial quedó fuera de servicio y otra parte fue requisada por los gobiernos respectivos para usos militares. Una aguda escasez de oferta impulsó al alza los fletes hasta convertirlos en causa importante de inflación y desequilibrio interno en muchos países. Todos los gobiernos intentaron, con mayor o menor fortuna, regular las condiciones del transporte marítimo para asegurar el abastecimiento y paliar el alza de precios. En estas circunstancias, los navieros que estuvieron en condiciones de operar obtuvieron enormes beneficios. En el caso de los países neutrales, en los que existía una menor presión oficial y cuyos barcos eran más respetados por los contendientes, las ganancias fueron de una magnitud todavía mayor ${ }^{8}$.

La flota mercante española estaba, pues, en las mejores circunstancias para aprovechar la coyuntura. Es bien sabido que los beneficios de las empresas navieras españolas experimentaron un incremento espectacular y que fracasaron los intentos del Gobierno para traspasar al Estado una parte de estos beneficios, obtenidos, en buena medida, a costa del bolsillo de los consumidores españoles ${ }^{9}$. No nos interesa aqui, sin embargo, el monto de esos beneficios, sino los ingresos en divisas que las actividades navieras generaban.

Desde esta perspectiva, lo primero que es necesario destacar es que la guerra provocó un intenso proceso de nacionalización del transporte marítimo. Como muestra el cuadro 5, antes del conflicto los barcos españoles sólo transportaban una tercera parte del comercio exterior español. Iniciada la guerra, tanto las entradas como las salidas de mercancías quedaron en mayor grado en manos de la flota mercante española. En el caso de las salidas, la recuperación duró poco. En cambio el transporte de las importaciones - siem-

- Véase un estudio detallado del impacto de la guerra sobre la industria naviera y los fletes en C. Ernest Fayle (1927).

- Roldán y García Delgado (1973), 1I, pp. 31-86. 


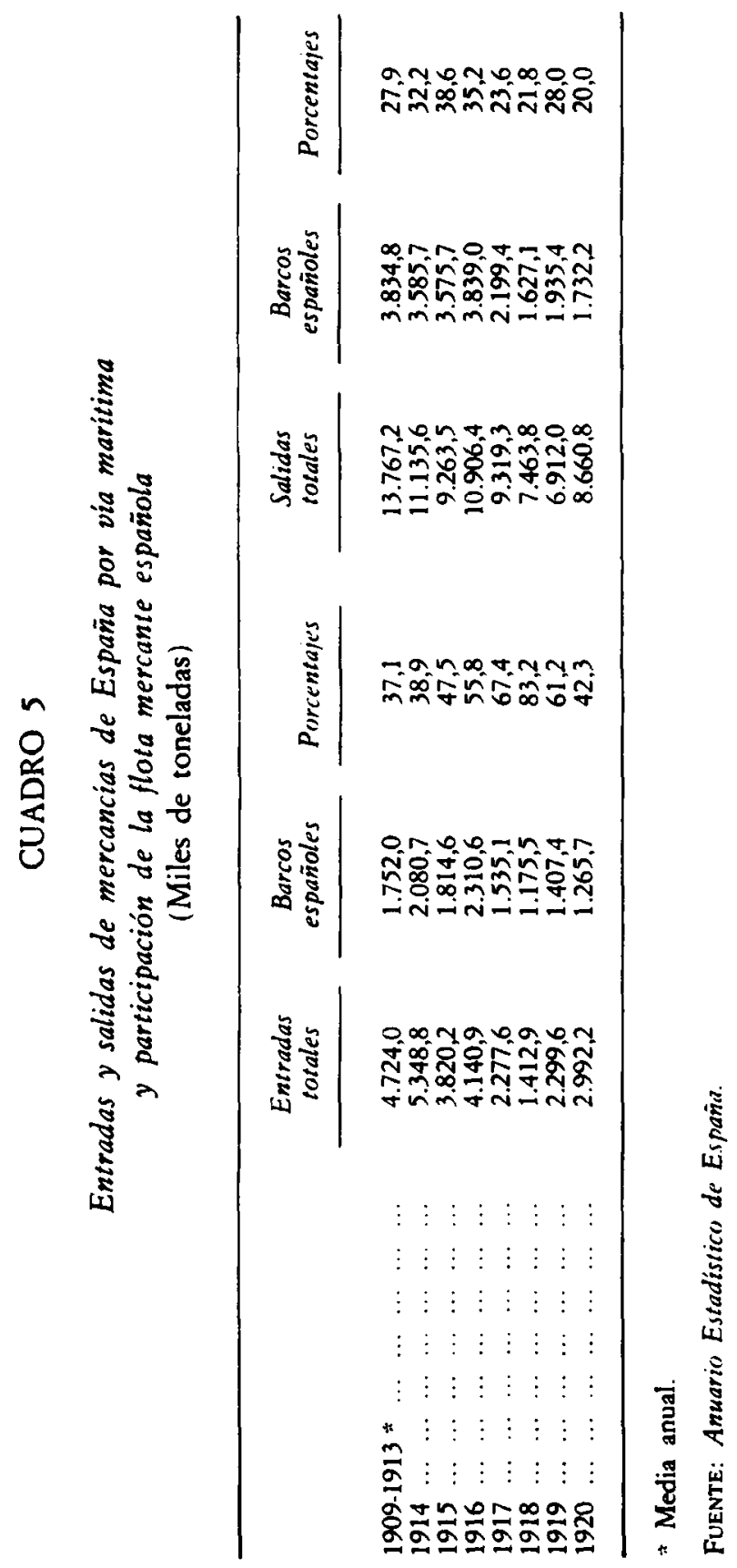


pre menos voluminosas- quedó mayoritariamente en manos españolas hasta finalizada la guerra.

El análisis de las cifras españolas, sin embargo, sólo de forma muy incompleta puede acercarnos al saldo de la balanza española de fletes. Como han indicado los mejores analistas de este sector, las empresas navieras españolas obtuvieron grandes beneficios transportando productos entre países extranjeros ${ }^{10}$. Como es lógico, las cifras propias del comercio español poco pueden aportarnos en este sentido. Para conseguir alguna indicación útil se hace imprescindible recurrir a las estadísticas de los países que eran los prin. cipales demandantes de transporte en aquellos momentos. En nuestro caso nos vamos a referir al Reino Unido y a los Estados Unidos, sin duda los dos principales mercados navieros en aquella época.

El cuadro 6 recoge la evolución del tonelaje neto de los barcos españoles salidos o entrados con carga en el Reino Unido y en los Estados Unidos. En conjunto, las cifras confirman algunos de los extremos anteriormente adelantados. En primer lugar, queda claro que la actividad naviera española se incrementó considerablemente desde el mismo momento en que estalló la guerra, tanto respecto a Gran Bretaña como respecto a los Estados Unidos. A partir de 1917 la situación cambió notablemente. Las regulaciones implantadas por el gobierno británico $y$, sobre todo, la guerra submarina, hicieron disminuir radicalmente la presencia de barcos españoles en puertos británicos. Nótese que el fenómeno es mucho menos agudo al otro lado del Atlántico, pese a detectarse también una inflexión. En los años posteriores al fin de la contienda, el tráfico fue tornando a la normalidad, pero con la importantísima diferencia de que una parte sustancial del comercio que antes pasaba por las Islas Británicas se dirigía ahora a los Estados Unidos.

Las cifras que comentamos nos van a permitir una aproximación a la evolución de la balanza exterior de fletes durante estos años. Hemos de tener presente primero que las estadísticas extranjeras citadas se expresan en toneladas netas de capacidad de carga y no en toneladas efectivas de carga real, que es lo que nos interesa. Para realizar la transformación he comparado las cifras de tonelaje neto de los barcos con carga entrados y salidos del Reino Unido y de los Estados Unidos procedentes o con destino a España con las que ofrecen las estadísticas oficiales españolas de navegación, que sí vienen expresadas en tonelaje efectivamente transportado. He establecido así una equivalencia para cada año y para cada país, que me ha permitido estimar el tonelaje que transportaron todos los barcos españoles entrados y salidos de los países citados, cualquiera que fuera su origen o destino. He procedido después a aplicar las tarifas de transporte utilizadas anteriormente para ajus-

${ }^{10}$ Roldán y García Delgado (1973), II, pp. 77-86. 


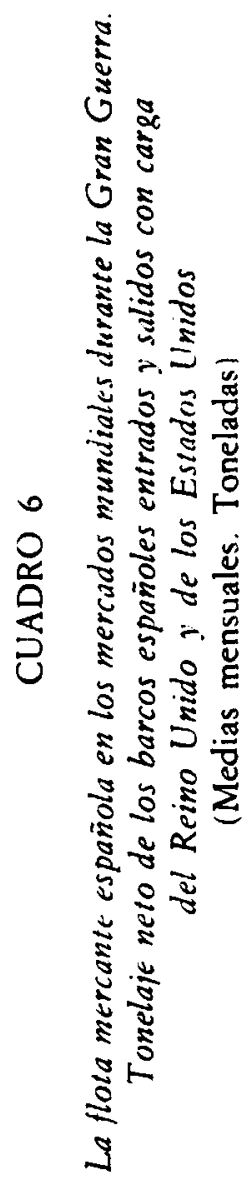

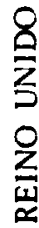

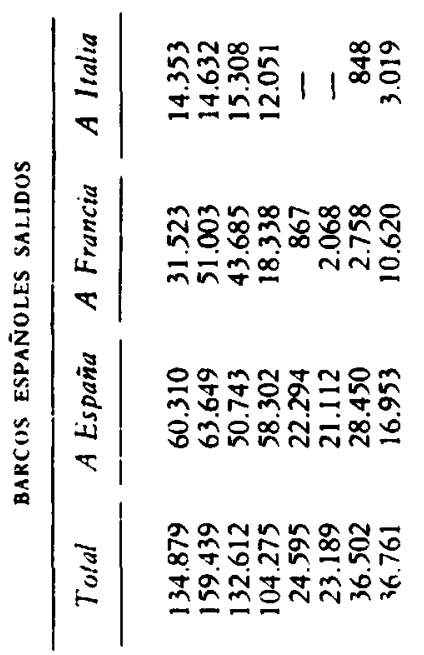

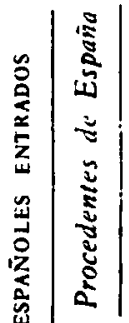

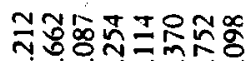

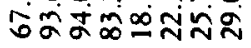

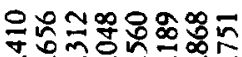
รiogn

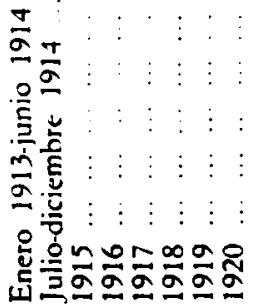




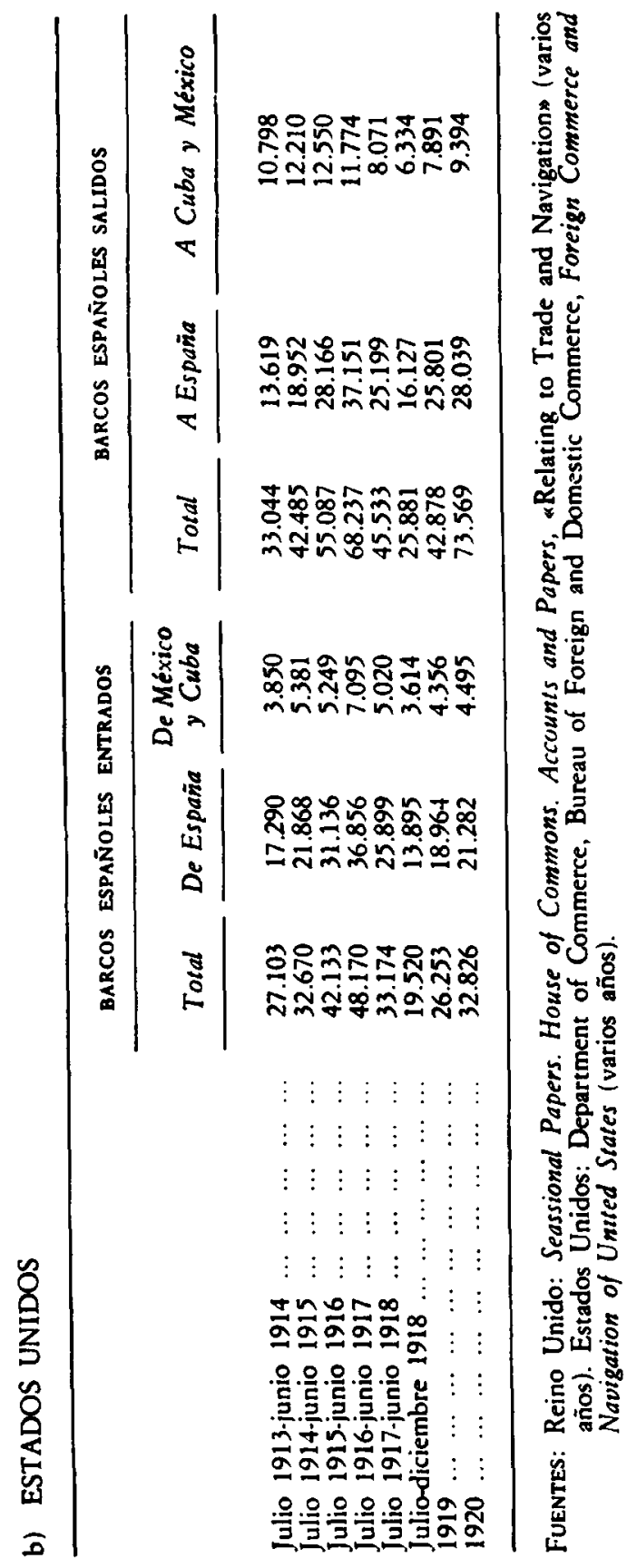


tar los valores de la balanza comercial. No se ha realizado una evaluación para cada país de origen y destino porque no lo permitían los datos de fletes, pero sí se han tenido en cuenta los casos del comercio entre el Reino Unido y Francia e Italia y entre Estados Unidos y México y Cuba. Finalmente, se ha procedido a estimar los ingresos de la totalidad de la navegación exterior española a partir del porcentaje que los dos países estudiados representaban en el conjunto del tonelaje salido y entrado de España. El cuadro 7 muestra el resultado de esta especulación.

\section{CUADRO 7}

Valor estimado de la balanza de fletes española (Millones de pesetas)

\begin{tabular}{|c|c|c|c|}
\hline & $\begin{array}{l}\text { Reino Unido y } \\
\text { Estados Unidos }\end{array}$ & Porcenlajes & Total \\
\hline 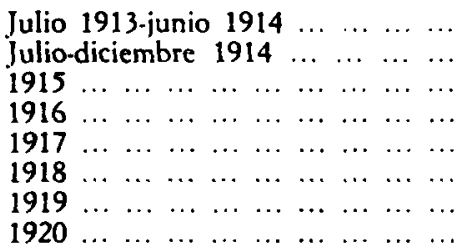 & $\begin{array}{r}41,8 \\
32,5 \\
121,5 \\
220,8 \\
226,3 \\
266,1 \\
83,7 \\
47,2\end{array}$ & $\begin{array}{l}49,8 \\
52,7 \\
63,0 \\
72,8 \\
74,7 \\
76,6 \\
67,2 \\
59,0\end{array}$ & $\begin{array}{r}83,9 \\
61,7 \\
192,9 \\
303,3 \\
303,0 \\
347,4 \\
124,5 \\
80,0\end{array}$ \\
\hline
\end{tabular}

Fuente: Véase texto.

Como era de esperar, los ingresos de la flota española en el exterior aumentaron espectacularmente desde el mismo momento de estallido de la contienda. Merece la pena resaltar que fue en los fletes transoceánicos donde se consiguieron los mayores beneficios. Sobre todo a partir de 1917, cuando quedó prácticamente paralizado el tráfico de barcos españoles con el Reino Unido. Queda claro también que la disminución de actividad provocada por la guerra submarina no afectó a los ingresos gracias, naturalmente, al enorme incremento que sufrieron los fletes. La aproximación que presentamos es muy arriesgada, en correspondencia a los muchos supuestos explícitos e implícitos que ha sido necesario aceptar para alcanzar algún resultado. Pese a ello no creo que las cifras propuestas resulten descabelladas. En 1918, El Economista estimaba los ingresos de la marina mercante española, para ese año, en 300 millones de pesetas ", y sabemos que los beneficios obtenidos por siete de las principales empresas navieras, entre las que no se incluian algunas de las más importantes, alcanzaron una media superior a los 60 millones de

"El Economista, 25 de mayo de 1918, p. 580. Citado por Young (1920), p. 86. 
pesetas entre 1915 y $1920^{12}$. Finalmente, es necesario subrayar que un error en la apreciación de los fletes tendería a compensarse en el conjunto de la balanza de pagos, ya que los hemos utilizado como factor negativo al calcular la balanza comercial y los utilizamos ahora como factor positivo ${ }^{13}$.

En definitiva, si aceptamos todas las suposiciones propuestas, la balanza de fletes para los años 1914-1920 se cerraría con un saldo positivo de 1.413 millones de pesetas, que es necesario añadir al arrojado por la balanza comercial.

La otra partida que cabe incluir en la balanza de servicios es la entrada y salida de fondos destinados a satisfacer el rendimiento de inversiones o a pagar las cesiones de técnicas. Nuestra información sobre estos extremos es muy escasa. Los esbozos de balanzas de pagos elaborados con anterioridad a 1914 ofrecen, sin embargo, algunas orientaciones. El saldo neto sería negativo en un monto situado entre los 50 y 100 millones de pesetas anuales ${ }^{14}$. Sin embargo, en las balanzas de pagos calculadas por Francisco Jáinaga para los primeros años $1930^{15}$, los saldos son reducidos y a veces favorables a España. Todo parece indicar que esta partida de ninguna manera podría alterar significativamente los resultados que venimos obteniendo. Debe tenerse presente que bajo los efectos de la Primera Guerra Mundial algunas de las más importantes sociedades extranjeras establecidas en España, y muy especialmente las mineras, sufrieron reducciones importantes en sus beneficios. Por otro lado, no hay que olvidar que es justamente a lo largo de los años que estamos estudiando cuando se produjo el proceso de nacionalización de valores que hizo descender radicalmente la deuda exterior pública y privada española, lo que forzosamente había de reducir la salida de fondos para el pago de réditos. Otro elemento a considerar es la existencia durante estos años de préstamos concedidos por la banca española a los países en guerra, que proporcionaron las rentas correspondientes ${ }^{16}$.

12 Roldán y García Delgado (1973), 1, pp. 120-121.

13 Existían, naturalmente, otros costes relacionados con el transporte marítimo: pagos por estancia en puertos, gastos e impuestos de carga, etc. Una parte de ellos deben considerarse como gasto a deducir de los fletes cobrados. Creo, sin embargo, que en conjunto se trata de cantidades de menor importancia teniendo en cuenta las magnitudes que estamos manejando. Las cifras ofrecidas por Francisco Jáinaga para los años 19311934 [Véase Chamorro y Morales (1976)] de los costes de estancia en puertos extranjeros resultan inverosímiles si los relacionamos con los ingresos por fletes. Recordemos que Jáinaga utilizaba las respuestas of recidas por las propias empresas armadoras y que, al contrario de lo que sucedía en el período que nosotros estamos estudiando, en los primeros años 1930 se produjo un descenso notable de los fletes y de los precios en general.

i" Chamorro (1976), pp. 151-156.

"Chamorro y Morales (1976).

16 Durante 1918 y 1919 se establecieron convenios de crédito con Francia, Estados Unidos y Gran Bretaña, por un importe total de 685 millones. Véase Young (1920), pp. 87-90. 
En definitiva, creo que el saldo neto por rentas de inversiones y por transferencias de tecnología, teniendo en cuenta la revalorización experimentada por la divisa española respecto a las extranjeras, no alcanzaría para el conjunto de años que estudiamos un monto superior a los 100 millones de pesetas.

\section{La balanza de transferencias: las remesas de emigrantes}

La última partida importante que nos queda para acercarnos a la balanza de pagos por cuenta corriente es la referida a las transferencias. El componente básico de esta partida eran los envíos de numerario que efectuaban los trabajadores españoles que desarrollaban sus actividades en el extranjero. Durante los años de la guerra el panorama de la emigración española cambió de forma notable. Si hasta entonces había sido América Latina el objetivo de los emigrantes, durante los años de la guerra lo fue Europa y, muy especialmente, Francia. Las autoridades francesas, enfrentadas a graves problemas de falta de mano de obra como consecuencia de las movilizaciones, hicieron una política favorable a la entrada de trabajadores españoles. Las cifras oficiales de emigrados presentan serios problemas debido a la gran importancia de la emigración clandestina. Sabemos, sin embargo, que en 1921 había en Francia 255.000 españoles, frente a los 106.000 residentes de 1911 , y sabemos también que en los meses inmediatamente posteriores al fin de las hostilidades, volvieron a España no menos de 100.000 personas. En definitiva, es probable que en los años de la guerra hubiera en Francia una media de 250.000 trabajadores españoles ${ }^{17}$.

La espectacularidad y la importancia social de esta emigración masiva a Francia no debe ocultarnos, sin embargo, que la principal fuente de transferencias exteriores eran los españoles residentes en América Latina. Para 1900, el Fomento del Trabajo Nacional calculaba que el 85 por 100 de las transferencias de emigrantes provenían de los países del Plata ${ }^{18}$. Hacia 1914-20 había instalados en el continente americano no menos de millón y medio de españoles ${ }^{19}$.

Las cifras ofrecidas por los contemporáneos son relativamente coincidentes. Se habla de unos ingresos anuales por este concepto de 200-300 millones de pesetas $^{20}$. Con mejor información, Francisco Jáinaga calculó que para 1931,

"Datos y cifras procedentes de Nadal (1984), pp. 197-202. Véase también Sánchez Jiménez (1984), pp. 284-291.

1. Chamorro (1976), p. 153.

"De ellos, 830.000 en Argentina, 404.000 en Cuba, 220.000 en Brasil, y 30.000 en México. Cfr. Sánchez Jiménez (1984), pp. 274-281.

20 Chamorro y Morales (1976), p. 109. 
el saldo de transferencias había ascendido a 190 millones de pesetas-oro, cifra confirmada al año siguiente. También sugiere Jáinaga que esta cantidad era inferior en un 30 por 100 a la posible para 1930 , cuando la crisis no era todavía tan profunda ${ }^{21}$. Podemos decir, pues, que en un año normal los ingresos españoles hubieran ascendido a 270 millones de pesetas-oro. Partiendo de esta estimación podemos realizar algunos cálculos para acercarnos a la cifra posible para el período 1914-20.

Tengamos en cuenta, primero, el caso francés. En 1930 había en Francia 350.000 españoles, un 40 por 100 más de los que hubo de media entre 1914 y 1920. Los salarios agrícolas, por otro lado, habian descendido en términos de oro en un 25 por $100^{22}$. Si suponemos estable la estructura de empleo de los emigrantes y una relación directa entre sus ingresos totales y las transferencias remitidas a España, podremos deducir que el montante de esas transferencias no pudo ser superior en los años de la guerra de lo que fue en 1930, siempre en términos de pesetas-oro.

En el caso de Argentina, el país latinoamericano con mayor colonia española, la situación era la siguiente. Entre 1920 y 1930 la entrada neta de emigrantes españoles se estima en unos 240.000 , con lo que es de suponer que la colonia española habría aumentado en un 20 por $100^{23}$. Si observamos que entre 1914.20 y 1930 los salarios medios se habían incrementado en Argentina en un 40 por 100 en términos de oro ${ }^{24}$, parece sensato pensar que los ingresos totales de los españoles emigrados en la república del Plata fueron en 1914-20, aproximadamente, un 60 por 100 de la cifra alcanzada en 1930.

Así las cosas, una estimación razonable de las entradas de divisas por transferencias de emigrantes durante los años 1914.20 podría situarse sobre una media anual de 180 millones de pesetas corrientes ${ }^{25}$, o, lo que es lo mismo, en un monto total de 1.200 millones de pesetas para el conjunto de los siete años considerados.

"Jáinaga (1969), p. 529.

"Hemos utilizado el salario medio del jornalero agrícola masculino, que era de 3,75 francos en 1915, 7 francos en 1918, 11 francos en 1920 (media adoptada, 7 francos) y de 22,5 francos en 1930. Cfr. Annuaire Statistique de la France.

${ }_{23}$ Las cifras españolas de emigración son muy inseguras. He utilizado aquí las publicadas por la Dirección General de Inmigración del Ministerio de Agricultura argentino. Véase Yáñez (1989) y Sánchez Alonso (1990).

${ }^{24}$ Los salarios monetarios aumentaron en torno a un 60 por 100 , según se deduce de las cifras recogidas por Tella y Zymelman (1967), pp. 317 y 399; y por Diaz Alejandro (1970), pp. 42-43. La cotización media del peso-papel entre 1914 y 1920 fue de $0,426 \$$ $y$ en 1930 de 0,367 \$. Cfr. Statistical Abstract of the United States.

${ }_{25}$ Considero, de acuerdo con los testimonios citados más arriba, que las remesas procedentes de Europa (estimadas en base al caso francés), representaban el 20 por 100 del total en 1914-1920, correspondiendo el 80 por 100 restante a las procedentes de América Latina (que seguirian la pauta argentina). 
No cabe duda de que ésta es una estimación extremadamente grosera. Hacemos caso omiso de los posibles cambios en el nivel laboral de los trabajadores españoles, del carácter familiar o individual de la emigración, del número medio de jornales trabajados, etc... Se trata, sin embargo, de una cifra cercana a la que los contemporáneos creían plausible.

\section{El excedente total y su empleo}

Este último y funambulesco ejercicio nos permite acercarnos ya al saldo de la balanza de pagos por cuenta corriente ${ }^{20}$. Esta magnitud es la que se suele manejar cuando se habla de «beneficios» de España durante la guerra. Representa los ingresos netos que obtuvieron el conjunto de residentes en España en sus relaciones corrientes con el extranjero, o sea en aquellas que no implicaban desplazamientos de fondos para fines de inversión o de adquisición de oro en barras o monedas.

Como se puede deducir de lo dicho hasta ahora, el tal «beneficio» quedaría fijado, según nuestros cálculos, en unos 4.500 millones de pesetas corrientes, para el período 1914-20. Fs una cifra superior a la propuesta por Young ( 3.600 millones) ${ }^{27}$, próxima a la avanzada por el profesor Sardà ( 5.000 millones) ${ }^{28}$, pero alejada de los 8.000 millones que propugnaba Francisco Bernis ${ }^{29}$. En todo caso se trata de un enorme volumen de recursos - de capacidad de compra en el exterior- que quedó en manos de algunos españoles con la posibilidad de utilizarlo con amplia libertad. Veamos qué salidas se le dieron.

La primera y más importante función que tuvo el excedente de la balanza por cuenta corriente fue la de incrementar las reservas de oro del Banco de España. A finales de junio de 1914 el Banco tenía en sus cofres 710,9 millones de pesetas en oro. En el segundo semestre se evidenció ya una ligera subida (720,3 millones a 31 de diciembre), pero el incremento importante se inició en el año siguiente. A 31 de diciembre de 1915, las reservas habian ascendido hasta 970,4 millones y los incrementos siguieron en los años inmediatamente posteriores hasta empezar a estabilizarse en el segundo semestre de 1917 y, después de un último salto en los meses centrales de 1918, quedar

${ }^{26}$ Evidentemente habría otras partidas que deberíamos considerar y que dejamos de lado en esta aproximación. La única que podría tener alguna importancia es la de pagos al exterior por cuenta del Gobierno, que quizá se vio afectada por la guerra colonial en Marruecos.

"7. Young (1920), p. 90.

24 J. Sardà (1987), p. 240.

* Bernis (s. f.), p. 45. 
prácticamente inmóviles hasta finales de 1920 con un montante algo superior a los 2.500 millones (cuadro 8 ).

\section{CUADRO 8}

\section{Reservas de oro del Banco de España \\ (Millones de pesetas)}

\begin{tabular}{|c|c|c|}
\hline & Total & Incremento \\
\hline 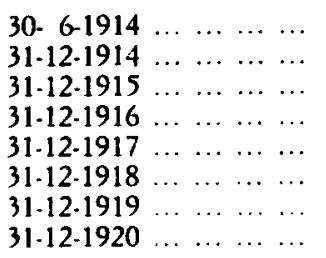 & $\begin{array}{r}710,9 \\
720,3 \\
970,4 \\
1.341,1 \\
2.055,9 \\
2.315,0 \\
2.506,3 \\
2.539,7\end{array}$ & $\begin{array}{r}\overline{9,4} \\
250,1 \\
370,7 \\
714,8 \\
259,1 \\
191,3 \\
33,4\end{array}$ \\
\hline
\end{tabular}

Fuente: Pablo Martín Aceña (1985), pp. 94-95.

El incremento para el conjunto del período considerado fue de $1.828,8$ millones de pesetas ${ }^{30}$. Como es natural, el Banco contabilizaba el oro según la paridad oficial ( 1 pesetas $=0,3226$ gramos de oro), pero lo había adquirido en parte a un precio inferior. Durante 1917, el Banco estuvo comprando dólares y libras de oro con una rebaja del 6 y del 2 por 100, respectivamente, en relación a la par. Pese a esta rebaja el incremento de oro registrado ese año - 715 millones, casi el 40 por 100 del total adquirido- fue mayoritariamente en dólares $(622 \text { millones })^{31}$. Este hecho puede resultar sorprendente si tenemos en cuenta que era justamente con los Estados Unidos con el único país importante con el que España mantenía déficit comercial. Durante estos mismos meses y los posteriores se produjo, además, una baja notable en la cotización del dólar-papel en los mercados españoles.

El doble fenómeno se explica por la alteración que sufrían los mercados de cambio internacionales. Las posiciones españolas en libras o francos - re-

* Las importaciones de oro registradas en las Estadísticas de Comercio Exterior eran inferiores a los incrementos que se deducen de los balances del Banco de España. Es teóricamente posible que el Banco adquiriera oro previamente existente en España en manos de particulares, pero parece más lógico pensar que algunas de las entradas de oro burlaron los controles aduaneros. Véase Martínez Méndez (1983), p. 588.

"A. Young (1920), p. 33. 
sultado del superávit de la balanza comercial y de servicios- eran transformadas en dólares para aprovechar el precio artificialmente alto al que los gobiernos respectivos mantenían las monedas europeas en el mercado de Nueva York. Los dólares así conseguidos representaban una cantidad muy superior a la necesaria para saldar el déficit de la balanza comercial hispanonorteamericana y se producía un exceso de oferta de dólares respecto a su demanda. Mientras fue libre la exportación de oro, buena parte de ese exceso fue convertido y el Banco de España, único comprador de oro en el interior del país, pudo aprovechar su situación de monopolio sin que ello privara de pingües beneficios a los especuladores ${ }^{32}$. Cuando el gobierno norteamericano empezó a poner limitaciones a la exportación de oro (finales de 1917), la cotización de dólar en los mercados españoles aceleró su descenso hasta alcanzar una depreciación superior al 30 por 100 (mayo de 1918) ${ }^{33}$. Esta situación tan anormal no podía perdurar y, efectivamente, la cotización se recuperó rápidamente en los meses siguientes. La compra-venta de dólares en estas circunstancias dio pie a notorios beneficios especulativos ${ }^{34}$.

La compra de oro por el Banco de España, por otro lado, supuso un incremento sustancial de la oferta monetaria y fue, sin duda, la causa principal del proceso inflacionario que se produjo en España durante estos años ${ }^{35}$.

Resumiendo, cabe decir que una parte sustancial —algo más del 40 por 100 - de los beneficios de la guerra quedaron almacenados en los sótanos del Banco de España. Salieron de allí veinte años después, en 1936, para ser utilizados por las autoridades republicanas en defensa del régimen de. mocrático que España se había dado a sí misma.

La segunda vía de aplicación de la capacidad de compra en el exterior obtenida durante la guerra fue la adquisición de valores españoles, tanto públicos como privados en manos de extranjeros. Por lo que se refiere a los valores públicos, el período que estamos estudiando contempla la práctica desaparición de la deuda exterior española. El Gobierno estimuló el proceso mediante diversas ofertas de conversión. A un ritmo creciente conforme el cambio del franco iba descendiendo, la deuda exterior era adquirida por ciudadanos españoles y, en algunos casos, canjeada por deuda interior. Hacia finales de 1917 se habían canjeado o domiciliado en España 513 millones de pesetas nominales, lo que representaba la mitad de la existente en manos foráneas en 1914. En 1921 sólo quedaban en el extranjero títulos por un total de 116,3 millones de pesetas. El nominal nacionalizado se podría evaluar, pues, a primera vista, en 900 millones, pero es preciso tener en cuenta

"A. Young (1920), pp. 96-98; y Martín Aceña (1984), p. 43.

"Martínez Méndez (1983), p. 565.

" Cambó (1920), pp. 6-7.

"Martín Aceña (1984), pp. 37-39. 
que una parte significativa de la deuda pública exterior estaba ya en manos de españoles con anterioridad a la guerra y su repatriación no supuso aplicación del excedente del período que analizamos. Conocedores del tema estimaban el nominal de la deuda cxterior en manos españolas en 1914 en 300 millones ${ }^{36}$. Los 600 millones realmente adquiridos a no residentes durante estos años lo fueron a tipos situados entre el 81,5 y el 88,2 por 100 , lo que significa que se invirtieron en ello unos 500 millones de pesetas corrientes, en forma de francos u otra moneda extranjera.

Más difícil resulta conocer las cantidades dedicadas a la adquisición en el exterior de valores privados de empresas españolas o de empresas extranjeras con negocio principal en España. Existen diversas evaluaciones sobre el volumen de la deuda privada exterior de España a principios del siglo $x \mathbf{x}$. El profesor Sardà ${ }^{37}$, después de estudiar todas las entonces disponibles, llegaba a la conclusión de que la cifra más probable se debía situar sobre los 3.500 millones de pesetas, de los que 1.300 millones corresponderían a empresas jurídicamente extranjeras con negocios en España ${ }^{38}$ y los 2.200 restantes a títulos de empresas españolas en manos extranjeras. Dentro de esta última cantidad, unos 2.000 millones serían valores ferroviarios. Esta evaluación parece concordar con la ofrecida recientemente por Albert Broder, teniendo en cuenta que con anterioridad a la guerra ya se habían producido compras de valores en el exterior por parte de residentes en España ${ }^{39}$.

¿Qué parte de esta inversión extranjera vigente al estallar la guerra fue adquirida por españoles? El propio Sardà asegura que, después del conflicto, las inversiones que continuaban en manos extranjeras no superaban los 2.000 millones ${ }^{4}$. Esto resultaría coherente con la idea de que el proceso de repa-

"solé Villalonga (1964), p. 54; Roldán y García Delgado (1973), I, pp. 361-364; y Barthe (1922).

3 J. Sardà (1987), pp. 224-226.

" Existe un censo detallado de estas empresas efectuado por la Dirección General del Timbre y recogido en «El capital extranjero en España», Revista Nacional de Economia. t. I, 1916, pp. 58-73.

37 Broder (1976) estima el montante de las inversiones efectivas de capital extranjero efectuadas entre 1851 y 1913 en empresas privadas que operaban en España en $3.265,2$ millones de francos. Si tenemos en cuenta el valor nominal de las acciones y obligaciones ferroviarias emitidas bajo la par y el de las obligaciones ya amortizadas en 1917, en base a las cifras del propio Broder recogidas por Nadal (1975), Apéndice 1; y Tedde (1978), pp. 256-257; se obtienc una cifra aproximada de inversiones nominales para 1913 de 4.017 millones de francos. Esta cvaluación no tiene en cuenta las transacciones de valores posteriores a la primera colocación y no parece exagerado estimar en 500 millones el nominal de los valores adquiridos por españoles con anterioridad a la Primera Guerra Mundial. En otra estimación que parece bien fundamentada, Cristóbal Massó atribuía al capital extranjero en plena guerra mundial un valor de 3.050 millones de pesetas. Cfr. Massó (1916), p. 63.

to J. Sardà (1987), p. 240. Young (1920), pp. 138-140, hace para 1919 una evaluación mucho más elevada, pero prácticamente olvida las compras de títulos habida durante la guerra. 
triación de inversiones privadas se habría concentrado en los ferrocarriles, alcanzando sólo de forma puntual y cuantitativamente poco importante a otros tipos de inversión ". Si consideramos, pues, que se produjo una adquisición de activos financieros en el extranjero por valor nominal de 1.500 millones y tenemos en cuenta la cotización media de los valores ferroviarios ${ }^{42}$ veremos que el efectivo desembolsado para adquirir esos títulos debió alcanzar, aproximadamente, los 900 millones de pesetas corrientes.

En último término, las posibilidades de inversión hasta ahora estudiadas - venta de oro al Banco de España, compra de deuda pública exterior y compra de valores privados- suman unos 3.250 millones de pesetas. Quedan pendientes 1.250 millones más que no encontraron colocación por estas vías.

El gobierno español intentó facilitar la financiación de este superávit impulsando la concesión de créditos en pesetas a gobiernos extranjeros. En 1918 y 1919 se firmaron convenios a estos efectos con Francia, Estados Unidos e Inglaterra por un importe de 455, 155 y 75 millones de pesetas, respectivamente, 685 millones de pesetas en total. En el caso de Estados Unidos y Gran Bretaña la operación resultó muy favorable para estos países, ya que pudieron devolver el importe en pesetas cuando el tipo de cambio respecto a sus monedas había descendido sustancialmente. Sólo en el caso francés el empréstito se prolongó más allá de 1920 y contribuyó a soslayar los efectos de la depreciación del franco ${ }^{43}$.

\section{El problema de la moneda extranjera}

De lo dicho hasta aquí se deduce que los excedentes de la balanza por cuenta corriente no colocados en oro ni en repatriación de valores españoles sólo podían retenerse en forma de depósitos o billetes en moneda extranjera o bien ser destinados a la adquisición de valores extranjeros no vinculados con España. Esta última posibilidad fue vetada por el Gobierno al decretar el 14 de junio de 1916 la prohibición de adquirir títulos extranjeros sin autorización previa del propio Gobierno. Es sabido que esta prohibición no fue respetada y que hubo inversiones en valores y bienes extranjeros ${ }^{4}$, pero, probablemente, las cuantías no fueron muy importantes. En las circunstancias azarosas de la

"1 Sobre el protagonismo de los valores ferroviarios en el proceso de repatriación durante los años de la guerra, véase Roldán, Muñoz y Serrano (1978), pp. 186-190.

12 Para las obligaciones de "Norte» y MZA, las corizaciones oscilaban entre el 64 y el 47 por 100. Véase Anuario Estadistico de España.

${ }^{\prime 3}$ Véase Young (1920), pp. 87.90; y noticias diversas en la Revista Nacional de Economia, vols. VIII, IX, X y XI (1920 y 1921).

* Lo asegura el propio Sardà (1987), p. 240; y también los observadores contemporáneos Cambó (1920), p. 13, y Barthe (1922). 
guerra y de la inmediata posguerra, las inversiones de este tipo representaban un riesgo enorme difícilmente asumible por individuos particulares, al margen de los problemas legales que la operación podía reportar en España y las posibles dificultades posteriores para repatriar los beneficios.

Así las cosas, en los últimos años del período que estamos estudiando se tuvo que producir una situación de grandes disponibilidades en moneda extranjera de difícil colocación. Una parte de estos saldos estaban depositados en cuentas bancarias, especialmente en las sucursales de entidades extranjeras. Otra parte circulaba en billetes y era objeto de activa especulación. La importancia de los saldos en moneda extranjera, tanto en bancos españoles como foráneos, es difícil de conocer. En el caso de la banca extranjera desconocemos, incluso, los saldos globales. Sí parece claro, en cambio, que la abrumadora presencia de entidades bancarias extranjeras en España durante estos años respondía a la existencia de estos recursos que of recían la posibilidad de financiar desde aquí mismo las exportaciones a sus respectivos países ${ }^{45}$. Estuvieran depositados o en forma de billetes, el hecho es que estas posiciones en moneda extranjera comenzaron a constituir un problema serio para sus tenedores, a partir del momento en que algunas de estas monedas empezaron a dar signos de extrema debilidad.

Como ya he indicado, las cotizaciones de las divisas de los países beligerantes no habian reflejado durante el conflicto el verdadero poder de compra relativo que éstas poseían. Acabada la guerra e iniciada la reconstrucción, las enormes pérdidas de riqueza y las grandes emisiones de billetes que se habian producido dejaron sentir su influencia sobre las cotizaciones. El franco, la moneda en la que se habían producido los mayores ingresos netos, empezó una vertiginosa caída a partir de mediados de 1919. De un valor próximo a 80 céntimos de peseta pasó en ocho meses a un valor de 40 céntimos. Fenómenos similares se observaron para el marco y la lira. La libra y el dólar, en cambio, mantuvieron o mejoraron sus cotizaciones (cuadro 9).

No podemos saber en qué monedas estaba reflejada la posición acreedora de los españoles, ya que se habian producido agios en todos los sentidos para aprovechar las fluctuaciones coyunturales. Existen indicios, sin embargo, de que los mayores saldos se mantenían en las monedas más afectadas por la depreciación. Los especuladores confiaban en el retorno de las monedas a las paridades fijas anteriores a la guerra, y es obvio que en ese caso el bene-

"La existencia en el interior de España de abundantes saldos en moneda extranjera y su manifiesta utilización como forma de pago hace difícil la estimación de la oferta monetaria efectiva durante este período. Los cálculos de Martín Aceña (1985) no incluyen la moneda extranjera en circulación y consideran sólo los depósitos en esas monedas existentes en los bancos españoles y aun bajo la consideración de depósitos a plazo, lo que sin duda minusvalora notablemente la oferta monetaria restringida (M1) y en menor medida las M2 y $\mathrm{M} 3$. 


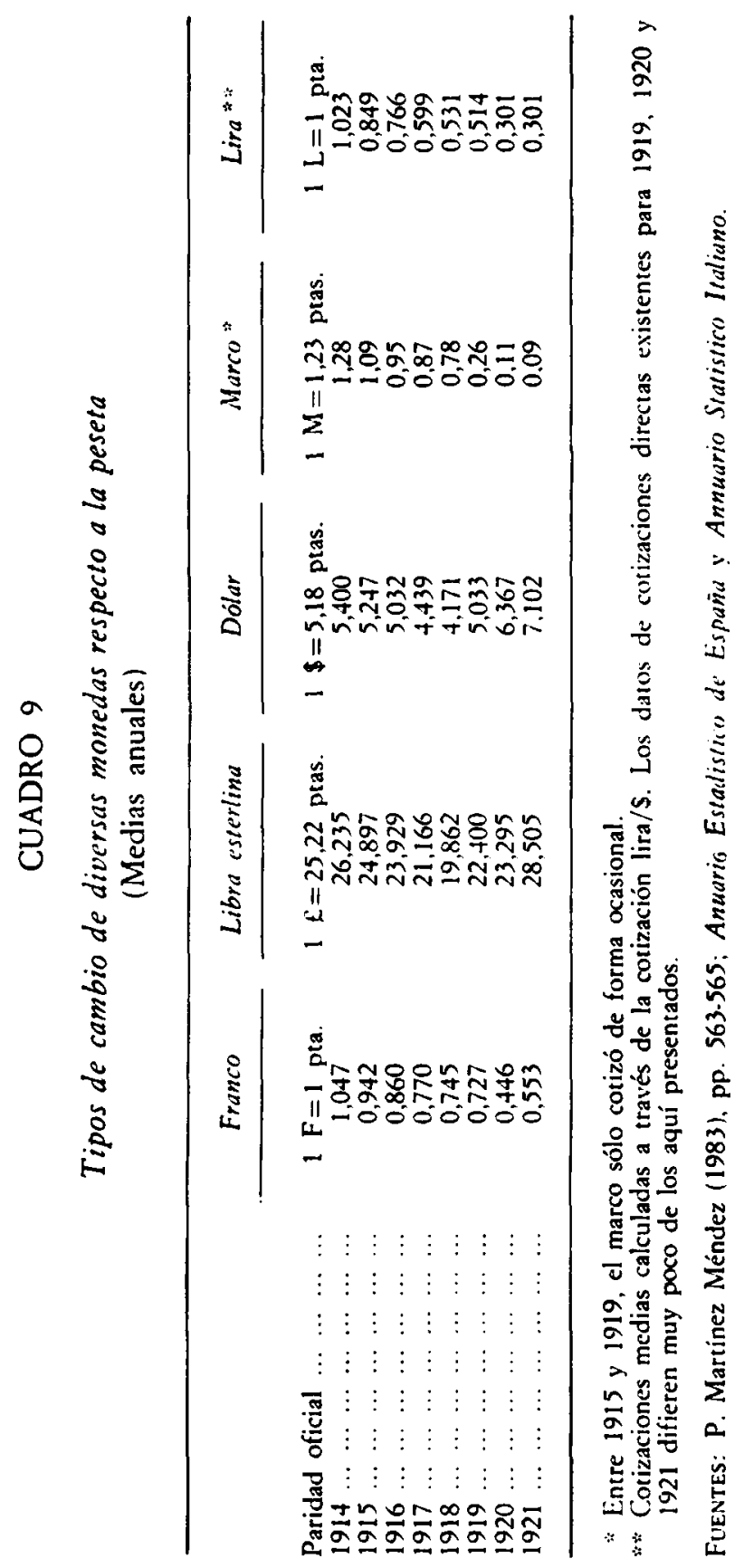


ficio sería tanto mayor como mayor fuera la depreciación. Cuando empezó a sospecharse que tales expectativas eran infundadas, cundió la alarma y surgieron algunas iniciativas para enfrentar la situación.

Por la categoría del personaje y por la amplitud y los apoyos y críticas con que contó su propuesta, destaca la formulada por Francesc Cambó en los primeros meses de $1920^{46}$. Su argumentación se iniciaba afirmando que la existencia de elevados saldos en moneda extranjera no era producto de maniobras especulativas, sino consecuencia de las dificultades existentes para transformar en activos reales los excedentes conseguidos en las relaciones corrientes con el exterior. Evaluaba en 1.500 millones el saldo de la balanza de pagos para 1919 y lo hacía coincidir con el volumen de moneda extranjera en manos españolas. Advertía inmediatamente el financiero y político catalán que no cabía esperar del franco, la lira y el marco un comportamiento parecido al del dólar, que, como ya he comentado, se había revalorizado después de una depreciación temporal. Las razones de la caida de las monedas europeas eran mucho más profundas y no era previsible una recuperación a corto plazo, más bien una devaluación formal.

La solución que proponía Cambó era inteligente y justifica la fama de su autor. La únima forma de evitar la depreciación - afirmaba- era convertir los billetes y cuentas corrientes en títulos que representaran activos físicos, en valores industriales de los países respectivos. Se hacía necesario, pues, derogar el decreto de prohibición antes citado, pero esto no era suficiente. Para el inversor individual, una operación de este tipo resultaría demasiado arriesgada, dadas las circunstancias internacionales. Cambó proponía formar un consorcio bancario que creara tres sociedades financieras, una para cada una de las monedas afectadas - el franco, el marco y la lira-, las cuales emitirían títulos en esas monedas que podrian ser adquiridos por los tenedores de las mismas. El capital conseguido se invertiría en valores del país respectivo, con la ventaja de poder diversificar el riesgo y negociar fórmulas favorables de inversión y de repatriación de beneficios. Se proponía también que los títulos emitidos fueran redescontables en el Banco de España con las consiguientes ventajas de liquidez para sus poseedores.

La propuesta de Cambó no estaba exenta de ambiciones personales. El monto de las inversiones controladas por el consorcio podía ser tal que la banca española accediera a los Consejos de Administración de todas las grandes sociedades de las que adquiriera títulos. El banquero catalán quería tener presencia en los centros de decisión económica más importantes de Europa.

Cambó consiguió interesar en la idea a los grandes bancos españoles,

* Cambó (1920). 
ellos mismos fuertes tenedores de moneda foránea, y constituir - a finales de marzo de 1920 - una sociedad denominada Trust Hispano Italiano, encargada de realizar la operación arriba indicada ${ }^{47}$. La iniciativa contó con la cerrada oposición de algunos de los más conocidos publicistas económicos de la época que aducían que se trataba de una operación especulativa que comportaba la salida de España de grandes capitales ${ }^{4}$. En agosto del mismo año, la sociedad lanzó una emisión de acciones por valor de 25 millones de liras, cosechando un notable fracaso: sólo se colocaron 7,1 millones. La sociedad se disolvió y los proyectos paralelos para francos y marcos quedaron olvidados ${ }^{4}$.

Tras este intento fallido, ignoramos cuál fue el destino final de los saldos en moneda extranjera que quedaron en manos de residentes en España. Dada la rapidez del proceso de depreciación, es de creer que buena parte de estos capitales se vieron severamente afectados por ella, con las consiguientes pérdidas para sus tenedores y para el país en su conjunto.

\section{Conclusion}

Expuestos los resultados de nuestra aproximación a la balanza de pagos española durante este período, llega el momento de concluir. Una nueva reflexión sobre el impacto de la guerra europea sobre la economía española queda fuera de la ambición de este trabajo. Permítaseme apuntar, sin embargo, que si bien ha sido posible confirmar algunas de las evaluaciones del profesor Sardà para este período, cabe discrepar de su valoración global. Los beneficios que la economía española obtuvo en su conjunto de la guerra europea sirvieron de poco. El oro adquirido por el Banco de España no fue utilizado para mejorar - vía importaciones- el equipamiento industrial del país, ni fue elemento suficiente para conseguir la incorporación al patrón-oro y sería finalmente gastado en la contienda civil. Los ferrocarriles cuyo capital se repratió no eran, precisamente, las empresas de capital extranjero más rentables e internacionalmente más influyentes de las instaladas en España. Los saldos en efectivo se evaporaron, en buena parte, en las inflaciones postbélicas. Quizá sea la eliminación de la deuda pública exterior lo que en el contexto del mundo de entreguerras tenga un componente más positivo.

${ }^{47}$ La constitución del consorcio hispano-italiano en Economia $i$ Finances, 25-4.1920,

p. 14; y Revista de Economía y Hacienda, vol. XXIII, 20-3-1920; p. 394.

4 Los más destacados, Luís Olariaga desde El Sol y Daniel Riu desde la Revista de Economia y Hacienda. Véase Olariaga (1920) y Riu (1920).

" Revista de Economia y Hacienda, vol. XXIII, 7-8-1920, pp. 1054-1056; 21-8-1920, p. $1130 ; 25-9-1920$, p. 1292 ; y $9-10-1920$, p. 1363. 
$\mathrm{Si}$, como se desprende de otros trabajos, la economía española era menos eficiente y menos competitiva en 1920 que en 1914 y ello dio lugar a un reforzamiento del proteccionismo ${ }^{50}$. Si, como parece establecido, los conflictos sociales de fondo que sufría la sociedad española no tan sólo no quedaron atenuados, sino que se agudizaron ${ }^{51}$, pocos elementos positivos, excepto el mayor enriquecimiento de grupos ya privilegiados, pudo obtener España de la situación creada por el conflicto europeo. El verdadero beneficio $-y$ no era poco- fue no participar.

so Entre 1910 y 1920 la productividad de la industria española parece haber descendido. Véase Carreras (1987), p. 292. Véase también Comín (1987), especialmente pp. 105-109.

"1 García Delgado (1984), pp. 71-73; y Tuñón de Lara (1984), pp. 585-589. 


\section{BIBLIOGRAFIA}

ANes, G.; Rojo, L. A., y Tedde, P. (eds.) (1983): Historia económica y pensumicms, social. Estudios en homenaje a Diego Mateo del Peral. Madrid, Alianza/Banco de España.

B^RTHE, A. (1922): «Empleo de los beneficios de la guerra realizados por Españam. Revista Nacional de Liconomia, t. XIl, pp. $403-410$.

Bernis, F. (s. f.): Fomento de las Exportaciones, Barcelona, Minerva.

Broder, A. (1976): "Les investissements étrangers en Espagne au XIXème siècle: methodologie et quantification». Revuc d'Histoire Fconomique ef Sociale, vol. 54. núm. 1, pp. 24-62.

(амво́. F. (1920): I:l problema de les monedes estrangeres. Barcelona, Ilenrich y (ïa.

(Aarkeras, A. (1987): "La industria: atraso y modernización», en Nadal, Carreras y Sudrià (comps.), pp. 280.312.

Cilamorro, S. (1976): «Bosquejo histórico de la balanza de pagos en España», Infor. mación Comercial Espaniola, núm. 517, pp. 151-156.

(unmorro, S., y Morales, R. (1976): "Las balanzas de pagos de Francisco láinaga», Información Comercial lispañola, núm. 511, pp. 107-118.

Comín, F. (1987): «La economía española en el periodo de entreguerras (1919.1935)». en Nadal, Carreras y Sudrià (comps.), pp. 105-149.

Diaz Aif.jandro, C. F. (1970): Essayss on conesmic history of the Argemine Kepublic. New Haven, lale University Press.

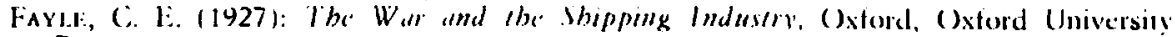
Press.

Fontana, I., y Nadal. I. (1980): "España, 1914.1970", en Cipolla (ed.). Histora l:a" nómica de liuropa. Vol. 6. Ecomomias comtemporáneas. Sezunda parte, Barceloma. Aricl, pp. 95.163.

García Dejgado, I. L. (1981): "La cconomía española entre 1900 y 1923", en Tuñón de Lara (dir.), Historia de España. Vol. VIll. Revolución burguésa, oligarquia y constitucionulismo (1824-1923), Barcelona, Labor, pp. 407.458.

- (1983): "Prosperidad y crisis de la industria española entre 1914 y 1922: una reconsideración», en Anes, Rojo y Tedde (eds.), pp. 539.560.

- (1984): «La industrialización española del primer tercio del siglo xxm, en Jover (dir.), pp. 3.171.

Instituto Nacional de Estadistica (1958): Comercto cexterior de España. Números in. dice's (1901.1956), Madrid.

IsSI:RLIS, L. M. A. (1921): “An index number of shipping freights", The Statist, Pp. 644.646 .

- (1938): "Index numbers of liamp Shipping Freights, 1836-1936\%, Journal of the Royal ficutistical Suciety, part I.

JáınacA, F. (1969): "Balance de pagos internacionales, año 1931\%, en Velarde (sel.), Lecturas de Lconomia Española, Madrid, Gredos, pp. 524-535.

Jover, J. M. (dir.) (1984): Historia de lispaña. Vol. X'XXVII. Los comienzos del siglo XX. La población, la economia, la socicdad (1898-1931), Madrid, Espasa-Calpe.

Maluguer de Motes, I. (1987): «De la crisis colonial a la guerra curopea: veinte años de economía española", en Nadal, Carreras y Sudrià (comps.), pp. 62-104.

Martín Aceña, P. (1984): La politica monefaria e'n lespaña, 1919-1935. Madrid, Instituto de Estudios Fiscales.

- (1985): La cantidad de dinero en lispaña, l\%o(1935, Madrid, Banco de España.

Martínez Méndez, P. (1983): «Nuevos datos sobre la evolución de la peseta entre 1900 y 1936m, en Anes, Rojo y Tedde (eds.), pp. 561-610.

Masso, C. (1916): "La nacionalización del ahorrom, Revista Nacional de Economia, t. I, pp. 60-68. 
NADAL. J. (1975): El tracaso de la Revolución industrial en España, 1814-1913, Barcelona, Ariel.

- (1984): La población española (siglos XVI a XX), Barcelona, Ariel.

NadAl, J.: Carreras, A., y Sudrià, C. (comps.) (1987): la economia española en el siglo $X X$. Una perspectiva bistórica, Barcelona, Ariel.

Ot.ariaga, L. (1920): «La exportación del capital español y su significación para el Estado y la economía nacional. Inconsecuencias del patriotismo financierom, Revista de Economia y Hacienda, XXIlI, pp. 657-658.

Ot.ıvarfs, A. G. (1916): "La marina mercante y los fletes en 1916», Revista Nacional de Economia, t. II, pp. $179 \cdot 196$

Palafox, J. (1980): “I.a crisis de los años 1930: sus orígenes", Papeles de Economia Española, núm. 1, pp. $30 \cdot 42$.

- (1986): "Comercio exterior y vía nacionalista. Algunas consideraciones", en García Delgado (ed.), La crisis de la Restauración. España entre la Primera Guerra Mundial y la Segunda República. Madrid, Siglo XXI, pp. 179-197.

Prados, L. (1982): Comercio exterior y crecimiento económico en España, 1826-1913. Tendencias a largo plazo. Madrid. Banco de España.

- (1984): "La evolución del comercio exterior, 1792.1929", Papeles de Economia Española, núm. 20 , pp. 133-150.

- (1986): «Una serie anual del comercio exterior español, 1821.1913», Rfvista dE His. TORIA ECONÓMICA, año IV, núm. 1, pp. 103.150.

- (1988): De Imperio a nación. Crecimiento y atraso económico en España (1780-1930), Madrid, Alianza.

Riv, D. (1920): "La emisión de acciones liras del Trust Hispano Italianom, Revista de Economia y Hacienda, XXIII, pp. 1052-1054.

Roldán, S., y Gakcia Delgado, J. L. (en colaboración con I. Muñoz) (1973): La formación de la sociedad capitalista en España, 1914-1920, Madrid, CECA.

Roldán, S.; Muñoz, J., y Serrano, A. (1978): «La vía nacionalista del capitalismo español», Cuadernos Económicos de ICE, núm. 5.

SÁnChez. Alonso, B. (1990): "Una nueva seric anual de la emigración española: 1882. 1930», Rfvista de Historia Económica, año VIII, núm. 1, pp. 133-170.

Sánchez Jıménfz. I. (1984): “La población, el campo y las ciudades". en Jover (dir.).

Sanderson, A. C. (1928): «Ocean Freights Rates in United States Forcign Trade», Trade Information Bulletin, núm. 434.

SARDÀ, J. (1987): "La política monetaria y las fluctuaciones de la economía española en el siglo xıX», en Escritos (1948-1980), Madrid, Banco de España [edición original: Madrid, CSIC, 1948].

SolÉ Vilialonga, G. (1964): La deuda pública española y el mercado de capitales. Madrid, Instituto de Estudios Fiscales.

Tedde, P. (1978): «Las compañias ferroviarias en España (1855-1935)», en Artola (dir.), Los ferrocarriles en España, 1844-1943. Madrid, Banco de España, vol. II, pp. 9.354.

Tella, G. Di, y Zymelman, M. (1967): Las etapas del desarrollo económico argentino, Buenos Aires, EUDEBA.

TENA, A. (1985): «Una reconstrucción del comercio exterior español, 1914-1935: la rectificación de las cstadísticas oficiales». Revista de Historia Económica, año III, núm. 1 , pp. 77-119.

- (1989): «Comercio exterior". en Carreras (coord.). Estadísticas bistóricas de España (siglos $X I X \cdot X X)$. Madrid. Fundación Banco Exterior.

TuÑón df LARA, M. (1984): «Estructuras sociales, 1898.1931», en Jover (dir.).

VAndellós, J. A. (1931): "La balanza comercial y el cambio de la pesetaw, Revista Nacional de Economia, t. XXX1I, pp. 3-17.

- (1977): «La riqueza y la renta de la Península lbćrica», en Schwartz (sel.), El produclo nacional de Lispaña en el siglo $X X$. Madrid, Instituto de Estudios Fiscales [edición original de 1925]. 
Vives, B. (1916): «La carestia de los fletes», Revista Nacional de Economia, 1, pp. 507-508. Yর̃Ñ:z, C. (1989): "Argentina como país de destıno. La emigración española entre 1860. 1930", Ponencia presentada al IV Congreso de la Asociación de Historia Económica. Alicante.

Younc, A. N. (1920): Spanish Finance and Trade. Washington, Department of Commerce, Bureau of Foreign and Domestic Commerce. 